\title{
The Effects of E-Learning Students' Lecture Participation on Satisfaction Level
}

\author{
Myoungjin Jung1)
}

\begin{abstract}
The purpose of this study is to understand the effects of e-learning students' lecture participation on their satisfaction levels. The study subjects were 174 students of technical colleges located in the city of Incheon. The SPSSWIN 21.0 program was used to conduct a frequency analysis, reliability analysis, and correlation analysis, while multiple regression analysis was conducted on the mediated effect. Study results showed that firstly, results of analyzing the difference in lecture participation of e-learning students according to general characteristics revealed that male students had higher recognition than female students of the e-learning system. Furthermore, males had higher participation in e-learning than females, while the overall participation in e-learning was highest in the following order of areas: duty-related education, certification education, university curriculum, and others. Secondly, when analyzing the difference in satisfaction level of e-learning according to e-learning students' general characteristics, it was shown that males had a higher satisfaction level in e-learning than females. Thirdly, when analyzing the effects of students' lecture participation in e-learning on satisfaction level, it was revealed that participants had a significant effect on the satisfaction level in the order of participatory characteristics. This study is expected to provide baseline data for improving the satisfaction level of e-learning students.
\end{abstract}

Keywords : e-Learning, Education, Service, Information, Communication, Lecture, Participation, Satisfaction

\section{Introduction}

\subsection{Necessity of Study}

With the sudden development of information and communication, all industries are applying information and communication technology. In particular, in the education area, smart machines are used to provide educational services ubiquitously through e-learning, which is becoming increasingly popular. Such e-learning students are increasing all across society, including in corporations and universities. The reason we use e-learning is the amount and quality of educational service are expected to improve greatly by creating a flexible learning environment

Received(June 28, 2019), Review Result(1st: July 22, 2019, 2nd: September 19, 2019), Accepted(November 15, 2019)

1) (Professor) 22212 Dept. Department of Airline Service Management, Inha Technical College., 100 Inha-ro, Michuhol-gu, Incheon. Korea

email: wjdaudwls1@naver.com 


\section{The Effects of e-Learning Students' Lecture Participation on Satisfaction Level}

that caters to the student's needs without limitations in space or time. The definition of e-learning is, 'an online learning system utilizing diverse forms of digital educational content via computer based on the internet and web which enables inter-communication between teacher and student'.

The components of e-learning are content for learning resources, connectivity that is necessary for connecting the content with the student through various delivery media and e-learning systems, and the community composed of students, teachers, and administrative staff who cooperate via smooth communication based on infrastructure and content[1]. Such results of e-learning are closely related to inter-communication between the lecturer and student; therefore, the e-learning content's role in the lecturer-student relationship also has a big effect on learning satisfaction levels.

Satisfaction levels of learning affect students' level of lecture participation. This is because the motivation to study is the biggest influencing factor in learning satisfaction, while the interaction between the teacher and student is the second biggest influencing factor, based on analysis results of studying influencing factors on the motivation and satisfaction of university-level nursing students[2]. Also [3], a study on the effects of motivation to study on satisfaction levels of cyber university students revealed that goal-oriented motivation to participate in learning, study-oriented motivation, and activity-oriented motivation all influenced the satisfaction level. Based on such results, it is evident that research on ways to improve lecture participation and e-learning content quality including faithfulness to the curriculum is mandatory for satisfying e-learning students.

In a study on the relationship between cyber university e-learning lecture students' participation variables and academic achievement, it was shown that the influencing factors were in the following order of gravity: attendance rate, number of times written on the debate board, and order of lecture room access. It was shown that there was a difference in the variables for lecture participation that affects academic achievement according to the background of each student[4]. Analysis of previous research revealed that additional research on variables affecting the motivation for lecture participation is mandatory for improving student satisfaction in lectures.

To improve the satisfaction level of students in the e-learning environment, the quality of the e-learning system content is important. This is due to the significant correlation between the satisfaction level of e-learning students and factors that determine content quality. In other words, qualitative factors that had a significant effect on e-learning student satisfaction were in the following order of gravity: information quality, service quality, and system quality[5]. 
Furthermore, when smartphones are used in e-learning, self-efficacy had a significantly positive

$\left.{ }^{+}\right)$effect on perceived utility and manageability, while perceived utility and manageability had a significantly positive $(+)$ effect on the intent to use a smartphone. This showed that there was a significantly positive $(+)$ effect on learning satisfaction levels[6]. Therefore, to improve the satisfaction level of students in the e-learning environment, we need to look for a detailed way that considers the content quality of e-learning content and participatory characteristics.

Based on such existing research results, it is evident that there is a need for more research on the effects of participation of e-learning students on their satisfaction levels. In previous research, there was partial research on participatory variables of e-learning students on their academic achievement but it is difficult to find study results on the effects of e-learning systems and participatory characteristics on their satisfaction level. Therefore, this study aims to provide baseline data to improve e-learning students' satisfaction levels by finding the effects of the e-learning system and participatory characteristics on e-learning satisfaction levels.

\subsection{Research Questions}

This study aims to analyze the effects of participation of e-learning students on their satisfaction level. The following are the research questions:

Question 1. How is e-learning students' participation level according to general characteristics?

Question 2. How is e-learning students' satisfaction level according to general characteristics?

Question 3. What is the correlation between e-learning students' participation level and satisfaction level?

Question 4. How does e-learning students' participation level affect their satisfaction level?

\section{Research Method}

\subsection{Subjects}

The subjects of this study are e-learning lecture students from 00 cities from January 10, 2019 until March 10, 2019. The survey was a self-administered questionnaire and was distributed after ample explanation to the subjects regarding the purpose of the survey. A total of 174 responses were collected and used for analysis. 


\subsection{Tools}

The tools used in this study consisted of 8 questions on the sociology of population, 6 questions on e-learning systems, and 6 questions on lecture participation. Content regarding the sociology of population comprised gender, age, education level, e-learning lecture name, duration of use, the experience of taking e-learning lectures, location of e-learning lecture, and field of e-learning lecture. To calculate the participation level of e-learning, tools used by Eunhee Kim[7] to calculate lecture participation, 6 questions about the subfactor e-learning system and 6 questions about participatory characteristics were used and each question used the 5-point Likert scale. Also, 4 questions used by Mingu Yeo[8] to calculate satisfaction level were used to calculate the satisfaction level in e-learning lectures.

\subsection{Reliability}

Verification of each variable's reliability in this study showed that the e-learning participation level's subfactor system had a reliability of .917 and participatory characteristics of .939 . The reliability of the e-learning satisfaction level was quite high at .942 . The Cronbach's a value of each calculation tool's reliability was .60 or more, securing reliability for this study. Reliability analysis results are shown in [Table 1] below.

[Table 1] Reliability of Major Variables

\begin{tabular}{c|c|c|c}
\hline \multicolumn{2}{c|}{ Category } & $\begin{array}{c}\text { Number of } \\
\text { questions }\end{array}$ & Cronbach's $\alpha$ \\
\hline \hline \multirow{2}{*}{$\begin{array}{c}\text { Participation } \\
\text { level in } \\
\text { e-learning }\end{array}$} & E-learning systems & 6 & .917 \\
\cline { 2 - 4 } & Participatory characteristics & 6 & .939 \\
\hline \multicolumn{2}{c}{ Satisfaction level in e-learning } & 4 & .942 \\
\hline
\end{tabular}

\subsection{Data Processing and Analysis Method}

The SPSSWIN 21.0 program was used to process collected data and was verified at the significance level of $5 \%$. Each research tool's reliability was calculated and analyzed using Cronbach's a quotient. A t-test and one-way ANOVA were conducted in order to find the difference in participation levels and satisfaction levels in e-learning per the general characteristics of the subjects. Through Scheffe's multiple range test, a significant difference of 
$\mathrm{p}<.05$ was confirmed.

\section{Study Results}

\subsection{Characteristics of the Sociology of Population}

When observing the characteristics of the sociology of the population of the study subjects, the following results are the general characteristics. For gender, 'male' was $67.5 \%$ and 'female' was $32.5 \%$. For ages, ' $21-23$ ' was $45.2 \%$, ' $18-20$ ' was $31.2 \%$, and ' $24-26$ ' was $23.6 \%$. For year, 'year 1 ' was $44.6 \%$, 'year 2 ' was $47.1 \%$, and 'year 3' was $8.3 \%$. For e-learning lecture name, 'university curriculum' was $51.0 \%$, 'certification education' was $18.5 \%$, 'other' was $15.3 \%$, 'duty-related education' was $12.7 \%$, and 'language education' was $2.5 \%$. For the duration of e-learning use, 'less than 6 months' was $72.0 \%$, '1-2 years' was 18.5\%, '6 months-1 year' was $7.0 \%$, and '2-3 years' was $2.5 \%$. For experience taking e-learning lectures, ' 1 time' was $45.9 \%$, ' 3 times or more' was $41.4 \%$, and '2 times' was $12.7 \%$. For location of e-learning lecture use, 'at home' was $66.2 \%$, 'at school' was $29.3 \%$, 'other' was $3.2 \%$, and 'PC room' was $1.3 \%$. For the field of e-learning, 'major subjects' was $43.9 \%$, 'liberal arts subjects' was $33.1 \%$, '(other) major subjects and liberal arts combined' was $14.6 \%$, 'other' was $7.6 \%$, and '(other) major subjects' was $0.6 \%$.

\subsection{Participation and Satisfaction Level in E-learning Lectures}

The following are the results of studying the participation and satisfaction levels in e-learning lectures. Participation in e-learning was highest in the following order: 'e-learning system' $(\mathrm{M}=3.25)$, and 'participatory characteristics' $(\mathrm{M}=3.20)$. The average satisfaction level in e-learning was 3.44. Reliability analysis results are shown in [Table 2] below.

[Table 2] E-learning Participation and Learning Satisfaction

\begin{tabular}{c|c|c|c|c|c|c}
\hline \multicolumn{2}{c|}{ Category } & N & Minimum & Maximum & Average & $\begin{array}{c}\text { standard } \\
\text { deviation }\end{array}$ \\
\hline \hline $\begin{array}{c}\text { Participation } \\
\text { level in } \\
\text { e-learning }\end{array}$ & $\begin{array}{c}\text { Participatory } \\
\text { characteristics }\end{array}$ & 157 & 1.00 & 5.00 & 3.25 & .75 \\
\cline { 2 - 7 } & $\begin{array}{c}\text { E-learning } \\
\text { systems }\end{array}$ & 157 & 1.00 & 5.00 & 3.20 & .85 \\
\hline \multicolumn{2}{c}{ Satisfaction level in e-learning } & 157 & 1.00 & 5.00 & 3.44 & .82 \\
\hline
\end{tabular}




\section{Verification of Research Questions}

Research question 1. Differences in participation level in e-learning according to the subjects' general characteristics.

1-1. Differences in the e-learning system according to the subjects' general characteristics

The following are the results of studying differences in e-learning systems according to the subjects' general characteristics.

Although there was a significant difference in the e-learning system according to the subject's gender, differences according to age, year, e-learning lecture name, duration, experience taking e-learning lectures, location of e-learning lectures, and field of e-learning lecture were insignificant. For gender, males $(\mathrm{M}=3.36)$ seemed to have a higher perception of e-learning systems than females $(\mathrm{M}=3.02)(\mathrm{t}=2.978, \mathrm{p}<.01)$.

1-2. Differences in participatory characteristics in e-learning according to the subjects' general characteristics

The following are the results of studying differences in participatory characteristics in e-learning according to the subjects' general characteristics.

Although there was a significant difference in e-learning participatory characteristics according to the subjects' gender and e-learning lecture name, differences according to age, year, duration, experience taking e-learning lectures, location of e-learning lectures, and field of e-learning lecture was less than $5 \%$ significance level. For gender, males $(\mathrm{M}=3.36)$ had higher participatory characteristics than females $(\mathrm{M}=2.88)(\mathrm{t}=3.894, \mathrm{p}<.001)$. For e-learning lecture name, duty-related education $(M=3.54)$, certification education $(M=3.45)$, university curriculum $(M=3.09)$, and other $(M=3.02)$ showed a higher participatory characteristic in this order $(F=2.856, p<.05)$.

Research question 2. Differences in satisfaction level in e-learning according to the subjects' general characteristics

The following are the results of studying differences in satisfaction levels in e-learning according to the subjects' general characteristics.

Although there was a significant difference in satisfaction level in e-learning according to the subject's gender, differences according to age, year, e-learning lecture name, duration, experience taking e-learning lectures, location of e-learning lectures, and field of e-learning lecture was less than $5 \%$ significance level. For gender, males $(\mathrm{M}=3.56)$ had a higher satisfaction level in e-learning than females $(\mathrm{M}=3.19)(\mathrm{t}=2.940, \mathrm{p}<.01)$.

Research question 3. Correlation between participation and satisfaction levels in e-learning 
The following are the results of studying the correlation between participation and satisfaction levels in e-learning according to the subjects' general characteristics. There was a positive correlation between the satisfaction level in e-learning and participation in e-learning in the following order: e-learning system $(\mathrm{r}=.698, \mathrm{p}<.001)$ and participatory characteristics $(\mathrm{r}=.686$, $\mathrm{p}<.001)$.

Research question 4. Effects of participation level in e-learning on the satisfaction level

Study results on the effects of participation level in e-learning on satisfaction level are shown in [Table 3] below. A multiple regression analysis was conducted to find the effects of participation level in e-learning on satisfaction level, which revealed that $\mathrm{R} 2=0.555$ and $55.5 \%$ of the total change. In order to diagnose multicollinearity, VIF (variable inflation factor) and tolerance were observed. Generally, if the variance inflation factor is 10 or more or the tolerance is less than 0.1 , it is construed that there is a problem of multicollinearity. In this study, the VIF was all 10 or less and tolerance more than 0.1 , revealing that there was no problem with multicollinearity. Results of variance analysis on the model showed that the estimated model was significant $(\mathrm{F}=95.900, \mathrm{p}<.001)$, while the e-learning system of participation level in e-learning had a significant effect on satisfaction level $(\beta=.424, \mathrm{p}<.001)$ and participatory characteristics $(\beta=.377, \mathrm{p}<.001)$ in this order, respectively. Therefore, it was revealed that the greater the participatory characteristics in e-learning, the higher the satisfaction level in e-learning would be.

[Table 3] The Effects of Lecture Participation on Satisfaction Level

\begin{tabular}{|c|c|c|c|c|c|c|c|}
\hline \multirow{2}{*}{\multicolumn{2}{|c|}{ Category }} & \multicolumn{6}{|c|}{ Dependent variable : Satisfaction level in e-learning } \\
\hline & & B & $\begin{array}{c}\text { Standard } \\
\text { error }\end{array}$ & $\beta$ & $\mathrm{t}$ & $\mathrm{p}$ & VIF \\
\hline \multicolumn{2}{|c|}{ (Constant) } & .772 & .200 & & $3.863^{* * *}$ & .000 & \\
\hline \multirow{2}{*}{$\begin{array}{c}\text { Participation } \\
\text { level in } \\
\text { e-learning }\end{array}$} & $\begin{array}{l}\text { E-learning } \\
\text { systems }\end{array}$ & .464 & .086 & .424 & $5.410^{* * *}$ & .000 & 2.127 \\
\hline & $\begin{array}{l}\text { Participatory } \\
\text { characteristics }\end{array}$ & .362 & .075 & .377 & $4.805^{* * *}$ & .000 & 2.127 \\
\hline
\end{tabular}

*** $\mathrm{p}<.001$

\section{Conclusion and Evaluation}

This study analyzed the effects of participation of e-learning students on learning satisfaction. 


\section{The Effects of e-Learning Students' Lecture Participation on Satisfaction Level}

The following is the conclusion based on the results.

Firstly, when analyzing differences in participation levels according to the general characteristics of e-learning students, there was a significant difference according to the subjects' gender but not age, year, e-learning lecture name, duration, experience taking e-learning lectures, location of e-learning lectures, and field of e-learning lecture. Males $(\mathrm{M}=3.36)$ seemed to have a higher perception of e-learning systems than females $(\mathrm{M}=3.02) \quad(\mathrm{t}=2.978, \mathrm{p}<.01)$. Furthermore, there was a significant difference in participatory characteristics in e-learning according to gender and e-learning lecture name. Males $(\mathrm{M}=3.36)$ had higher participatory characteristics than females $(\mathrm{M}=2.88)(\mathrm{t}=3.894, \mathrm{p}<.001)$. For e-learning lecture name, duty-related education $(M=3.54)$, certification education $(M=3.45)$, university curriculum $(M=3.09)$, and other $(\mathrm{M}=3.02)$ showed a higher participatory characteristic in this order $(\mathrm{F}=2.856, \mathrm{p}<.05)$. Such results coincide significantly with study results that show that even when analyzing e-learning strategies' effects on participation, achievement, and satisfaction in the university blended learning environment, males showed to have a higher learning strategy than females[9].

Secondly, when analyzing differences in satisfaction levels in e-learning according to the general characteristics of students, there was a significant difference according to the subjects' gender but not age, year, e-learning lecture name, duration, experience taking e-learning lectures, location of e-learning lectures, and field of e-learning lecture, as their significance level was less than $5 \%$. For gender, males $(\mathrm{M}=3.56)$ had a higher satisfaction level in e-learning than females $(\mathrm{M}=3.19) \quad(\mathrm{t}=2.940, \mathrm{p}<.01)$. Such results coincided with study results that show that the male group reacts more sensitively than female groups in regards to the influence of user convenience on user-content composition interaction and user-content substance interaction as a result of analyzing influencing factors on e-learning satisfaction focusing on gender differences[10].

Thirdly, when analyzing the effects of e-learning students' lecture participation on satisfaction level, it was revealed that the e-learning system of participation level in e-learning had a significant effect on satisfaction level $(\beta=.424, \mathrm{p}<.001)$ and participatory characteristics ( $\beta=.377, p<.001$ ) in this order, respectively. Therefore, it was observed that the higher the e-learning system and participatory characteristics, the higher the satisfaction level in e-learning was.

Such results coincide with results of studies that analyze the correlation between motivation to participate in lectures and satisfaction level which revealed that there was a significant positive correlation between motivation to participate, participation, and satisfaction, as well as results that showed that the higher the motivation to participate and participation level, the 
higher the satisfaction level is (Hyesook Ha, Minji Park, 2019). This shows that in order to improve the satisfaction level of e-learning students, systematic intervention to raise their motivation to study and participate actively in lectures is essential.

There is a need to study the effects of moderating the study community in regards to the improvements that student participation incurs in achievements.

\section{References}

[1] S. Yang, A Survey of Actual Conditions of e-Learning in Universities, The Journal of Internet Electronic Commerce Research, (2012), Vol.12, No.4, pp.289-304, UCI: G704-001762.2012.12.4.012

[2] Mi-Kyoung Cho, Mi Young Kim, Effects of Learner Motivation and Teacher-student Interaction on Learner Satisfaction in Nursing Students, The Journal of the Korea Contents Association, (2017), Vol.17, No.4, pp.468-477, DOI: $10.5392 /$ JKCA.2017.17.04.468

[3] Hyo-yeon Lim, Soon Min Lee, A Study Exploring the Relationship of Educational Participatory Motivation and Educational Satisfaction among Adult Social Work Students of a Cyber University, The Journal of the Korea Contents Association, (2014), Vol.14, No.10, pp.403-415, DOI: 10.5392/JKCA.2014.14.10.403

[4] M. S. Kang, J. I. Kim, I. W. Park, The Examination of the Variables related to the Students' e-learning Participation that Have an Effect on Learning Achievement in e-learning Environment of Cyber University, Journal of Internet Computing and Services, (2009), Vol.10, No.5, pp.135-143, UCI: G704-001022.2009.10.5.012

[5] Jong-Yeon Lee, Eun-Jin Lee, Influence Analysis of System, Information and Service Qualities on Learner Satisfaction in University e-Learning, The Journal of Educational Studies, (2010), Vol.41, No.3, pp.119-147, UCI: G704-001618.2010.41.3.006

[6] Ki-Hun Pak, Young-Min Kim, A Study on Smart Phone based e-Learning and its Impact on Learner's Satisfaction, The E-business Studies, (2013), Vol.14, No.2, pp.25-45, DOI: 10.15719/geba.14.2.201306.25

[7] E. H. Kim, The Structural Relationship between Learning Engagement and Learning Effect of e-LearningFocused on Customer Center Workers -, Interdisciplinary Program of Electronic Commerce Graduate School, Chonnam National University, Doctoral Dissertation, (2017)

[8] Min Koo Yeo, The Relationship Analysis of e-Learning Service Quality, Satisfaction and Repurchase Intention, Major in Educational Technology Graduate School of Education Sogang University, Master Thesis, (2012)

[9] Mi Young Kim, E-Learning Strategies Affecting the Levels of Participation, Achievement and Satisfaction in the University Blended Learning Environment, The Journal of Korean Association of Computer Education, (2007), Vol.10, No.4, pp.93-102, DOI: 10.32431/kace.2007.10.4.009

[10] Tae Ung Kim, Myoung Yong Um, Gender Differences in Perceptions and Relationshipsamong Determinants of User Satisfaction in e-Learning, Korean Management Review, (2006), Vol.35, No.1, pp.51-80, UCI: G704-000126.2006.35.1.002 